\title{
O que fazer com o que as aulas remotas fazem comigo? Posição subjetiva de estudantes de uma escola pública
}

\section{What to do with what remote classes do with me? Subjective position of students at a public school}

https://doi.org/10.34112/2317-0972a2021V39n82p109-124

\author{
EANES DOS SANTOS CORREIA ${ }^{1}$ \\ Veleida Anahi da Silva ${ }^{2}$ \\ Willdson Robson Silva do Nascimento ${ }^{3}$
}

RESUMO: O presente artigo tem o objetivo de discutir a posição subjetiva e bricolagem de estudantes do ensino médio de uma escola pública estadual da região agreste do estado de Sergipe, diante de aulas remotas dadas pelo aplicativo Google Meet, disponível gratuitamente na plataforma digital Google. Pensando sobre o que acontece do outro lado da câmera com os estudantes, chegamos à principal questão de investigação: quais bricolagens os estudantes utilizam quando estão on-line nas aulas remotas? A discussão e análise se dão com foco nas noções de posição subjetiva da Relação com o Saber, de Bernard Charlot (2000; 2005; 2013), e de bricolagem, de Michel de Certeau (1998). Enquanto sujeitos de relações consigo mesmos, o outro e o mundo, os estudantes não são passivos à ortopedia da Educação; eles também têm desejos, objetivos e metas, e estão sempre em mobilização para alcançá-los a curto ou longo prazo.

Palavras-chave: Aulas remotas; escola pública; relação com o saber.

ABSTRACT: This article aims to discuss the subjective position and bricolage of high school students from a state public school in the rural region of the state of Sergipe regarding remote classes through Google Meet application provided freely by Google digital platform. Thinking about what happens with students on the other side of the camera, we come to the main

1. Universidade Federal de Sergipe - UFS, Brasil.

2. Universidade Federal de Sergipe - UFS, Brasil.

3. Universidade Estadual Paulista "Júlio de Mesquita Filho", Bauru, SP, Brasil. 
O que fazer com o que as aulas remotas fazem comigo? Posição subjetiva de...

research question: what do students do when they are online in remote classes? In order to make a discussion and analysis of this study, the text focus on the notions of subjective position of the Relationship based on the concept of Bernard Charlot (2000; 2005; 2013) and bricolage by Michel de Certeau (1998). As subjects of relationships with themselves, the other and the world, students are not passive to the orthopedics of Education, they also have desires, objectives, goals and are always in mobilization to reach them in short or long term. KEYWORDS: Remote lessons; public school; relationship knowledge.

\section{INTRODUÇÃO}

Em tempo de pandemia, os professores tiveram que se reinventar com os poucos recursos tecnológicos que têm para continuar dando aulas de maneira remota nas escolas públicas de Educação Básica do Brasil. Nesse período, docentes e estudantes provavelmente já ouviram ou falaram "Ligue a câmera!”, "Professor, minha internet tá ruim, por isso a câmera não está ligada!”, “Tem alguém aí?”, “Não estou ouvindo e nem vendo ninguém. A internet de vocês caiu?", "Professor, vai ter prova mesmo com essas aulas on-line?", "Parece que estou dando aula para as paredes da minha casa!". Os problemas são muitos, a precariedade de instalações de rede de internet e de aparelhos que tenham acesso aos Apps para a efetivação das aulas é diversa.

Sabe-se que nem todos os estudantes têm tablet, smartphone, computador ou outros aparelhos digitais que auxiliem no acesso às aulas remotas, assim como os professores não possuem instalações básicas para a produção das aulas e também para armazená-las virtualmente (UNESCO, 2020). Assim, diante das experiências dos professores pesquisadores deste artigo, presenciando, observando e participando de aulas neste contexto, surgiu um questionamento: o que acontece do outro lado da câmera com os estudantes que participam dessas aulas? Ou seja, quais bricolagens os estudantes utilizam quando estão on-line nas aulas remotas?

Partimos de dois pontos de vista nesta investigação: o primeiro é sustentado a partir da posição subjetiva dos discentes diante das aulas remotas, com a noção de Relação com o Saber, de Bernard Charlot. Já o segundo ponto se desdobra sobre o que eles fazem ou usam a título de bricolagens durante as aulas para conseguir assisti-las, sem ter que adquirir ônus durante o período letivo, a partir da perspectiva de bricolagem de Michel de Certeau. 


\section{BRICOLEUR}

Em Invenções do Cotidiano, livro de Michel de Certeau (1998), o autor desenvolve a economia do conceito de táticas e estratégias cotidianas que vivenciamos, como formas de viver uma vida comum. No desenvolvimento da sua obra, Certeau (1998) mostra as possibilidades de uso de táticas, com o objetivo de se esquivar do pesado e doloroso fardo da realidade, das obrigações diárias, das angústias permanentes da vida, procurando formas de se relacionar, viver, amar, produzir, estudar, enfim, de sobreviver em meio à burocracia, às regras, às leis e à realidade nociva à maioria da população dentro de uma sociedade capitalista neoliberal.

Certeau traz uma concepção de práticas ordinárias que está em cada sujeito. Olhando para os modelos de práticas ordinárias, cada um dos sujeitos age, pensa e reflete sobre o mundo e suas práticas na sua cultura.

Nesse viés, Certeau não considera as pessoas meras receptoras passivas da linguagem, da cultura sobre elas e suas práticas, mas sujeitos que estabelecem sínteses, que fazem bricolagens, que arrumam soluções e trabalham com as possibilidades a fim de produzir algo que lhes dá sentido. Esses sujeitos não são passivos, mas produtores ativos, numa posição subjetiva - temos assim formas de pensar do sujeito a partir de uma posição social e de como ele determina essa posição através de projeções presentes e futuras dentro de uma lógica simbólica -, a partir de sua posição social objetiva - da classe social, econômica e intelectual que se estabelece sobre a pessoa a partir dos sensos sociais por meio de critérios econômicos e escolar/ acadêmico. Como sujeitos de saber, as pessoas vão elaborando sua forma de viver, de se sobressair em uma determinada situação ordinária.

Isso faz com que o sujeito de relação possa se identificar, refletir e agir diante de suas relações sociais, escapando de forma ativa e autônoma de dadas situações que lhe são impostas. Isso é uma forma, segundo Certeau, de produzir outro conhecimento ou saber, ou seja, formas de se relacionar e viver, o que ele designa como bricoleur, ou seja, bricolagem.

Bricoleur é uma contribuição de Certeau que nos permite perguntar: "o que os sujeitos fazem com as informações que chegam até eles e o que fazem com os objetos que lhes são impostos?” Dessa forma, o autor abre possibilidade para um campo da subjetividade do sujeito, de sua posição subjetiva, enquanto sujeito histórico, singular e social, dando lugar às dimensões identitária, social e epistêmica dos sujeitos em sua relação com o saber (CHARLOT, 2000; 2005; 2013). 
O que fazer com o que as aulas remotas fazem comigo? Posição subjetiva de...

Dessa forma, a compreensão que Certeau tem das práticas ordinárias dos sujeitos insubmissos nos leva a compreendê-los como sujeitos do desejo, que se mobilizam a fazer tal ou qual prática, ou seja, sujeitos que sintetizam, que assimilam as informações que são oferecidas, às quais não se submetem e "fogem da ordem". Dessa forma, coadunando com o pensamento de Certeau, Charlot (2000; 2005; 2013) também traz essa posição subjetiva do sujeito como uma contribuição direcionada aos sujeitos de desejo para se pensar a educação e os estudantes, que se mobilizam para aquilo que lhes faz sentido, que rejeitam ou que decidem entrar em uma atividade intelectual para aprender na escola, principalmente na sala de aula, e, no nosso contexto, em um ambiente virtual remoto.

O pensamento desse sujeito fora de ordem de Certeau vai de encontro ao pensamento de uma ordem que se estabelece entre a década de 70 e 80 , bastante conhecida pela obra A Reprodução, de Bourdieu e Passeron (1992), que defende que a escola é uma máquina de reprodução social, ou seja, na medida em que a escola se estabelece em um todo social, ela é ao mesmo tempo uma máquina de reprodução desse todo social.

Diante desse pensamento de que a escola é reprodutora do Estado e das ordens vigentes estabelecidas, pensar a partir de Certeau sobre os sujeitos como insubmissos e não como agentes de reprodução somente, leva-nos a pensar no sujeito do desejo como uma posição subjetiva de Charlot (2000; 2005; 2013), ou seja, a forma como as lógicas sociais funcionam na cabeça das pessoas; no contexto deste trabalho, na cabeça dos estudantes de uma escola pública estadual do estado de Sergipe.

Dessa forma, pensar os estudantes como sujeitos de desejo, que pensam, agem e se mobilizam no espaço escolar é uma oportunidade de se colocar em discussão esses estudantes, que usam de meios próprios para se sobressair às regras da escola e conseguir tanto transgredir, quanto se afiliar às suas lógicas simbólicas sobre estudar, ensinar, colar, aprender e ser aprovado durante o ano letivo escolar.

É a partir desse viés de pensamento certeauniano e charlotiano, de uma razão subjetiva do estudante - no nosso contexto - que se abre a possibilidade de pensar o que os estudantes fazem com as aulas remotas, os métodos e os aparelhos tecnológicos utilizados dentro da seara da educação em um ambiente virtual. Isso nos faz refletir para uma tomada de ação posterior, a partir da perspectiva do estudante sobre a bricolagem, a própria rebeldia, a inovação, o estranhamento, a (re) significação, a adaptação e a própria negação do ensino, de estudo de colocar em xeque normas, regulamentos e a própria ordem do regimento escolar. 
DialÉTICA DA POSIÇão OBJETIVA E SUBJETIVA DOS ESTUdANTES

Viver é habitar uma posição social. Ao nascermos adentramos no mundo estratificado em classes. A linguagem, com suas lógicas simbólicas - não naturais - interpela os sujeitos dando-lhes um nome, um sobrenome, um tipo sanguíneo, uma cultura, uma nacionalidade, um número de registro, cuidadores, família, uma cor, uma língua e uma classe social, a partir do que todas as pessoas são identificadas para a promoção de ser um sujeito de direitos e deveres em direção ao universal humano.

A posição objetiva do sujeito ao mesmo tempo o estigmatiza, rotula e o coloca em um determinado espaço e tempo, no que diz respeito à sua dimensão social, o faz ser de forma concomitante um sujeito de desejo e singular, pois através de relações com os outros e o mundo num determinado espaço e tempo, leva-o a ser não somente um sujeito social, mas também um sujeito singular que pensa, age, movimenta e modifica seu meio.

É pensando a partir desse movimento de relação entre posição social objetiva e subjetiva que podemos concluir que para ter ou estar em uma posição social subjetiva, o sujeito esteja antes, durante e posteriormente também em uma posição social objetiva ordinária.

É através dessa unidade dialética de posições que as pessoas permanecem em suas posições, se transformam e se mobilizam de onde estão, a partir do meio em que se encontram, tanto fisicamente como intelectualmente. É nesse espaço da razão subjetiva de Certeau (1998) - do sujeito insubmisso e fora de ordem -, e de Charlot (2000; 2005; 2013) - do sujeito de desejo que se mobiliza porque encontra sentido e prazer nisso ou naquilo -, que a posição subjetiva encontra seu lugar privilegiado nas transformações que ocorrem entre os sujeitos de relação que refletem a partir das condições que lhes são dadas.

O mundo se (trans)forma pelo outro, por meio de relações entre as pessoas, os objetos e o mundo em um determinado tempo e espaço social. É no movimento dessas relações entre os sujeitos que as ideias, as invenções, as tecnologias, as grandes construções humanas se desenvolvem. Antes de qualquer teorização, o homem é um ser de relação e de desejo. Por esse estatuto, o homem entra em um processo de socialização e singularização e nesse mesmo processo se torna humano. Afeta, é afetado, desenvolve teorias, ama, mente, aprende, ensina, se submete a isso ou àquilo, torna-se insubmisso, dá ordem e obedece, formula leis, infringe as leis, torna-se 
O que fazer com o que as aulas remotas fazem comigo? Posição subjetiva de...

rico e miserável, leigo e intelectual. A cada momento que o homem se relaciona faz tecituras de um mundo cada vez mais humano e de contradições dialéticas.

É a partir dessas relações de contradições que o nosso ponto de vista se amplia neste texto, pois os estudantes sobre os quais estamos discutindo se encontram nesse entremeio, como sujeitos que, a partir de sua razão subjetiva, segundo Certeau, criam seus modos de viver, de se sobressair em uma determinada situação; e, a partir da sua posição subjetiva, segundo Charlot, conseguem mudar de situação social a partir de sua mobilização motivada por um desejo de aprender e de mudar de posição social.

Destarte, compreender as posições sociais objetivas e subjetivas como unidade dialética nos faz verificar que, mesmo que uma pessoa esteja numa determinada posição social, ela pode permanecer, sair dela e transformá-la, por considerarmos que o sujeito de desejo se movimenta, transita entre essas posições, pois uma posição se encontra em nível de subjetividade (na cabeça do estudante) e a outra dentro de relações significantes (nas lógicas simbólicas estruturadas socialmente). O sujeito pode ser múltiplo em sua subjetividade e ao mesmo tempo ocupar a mesma ou outra posição social estruturada. Nesse sentido, o que determina toda essa movimentação, dinâmica e percurso é a relação que o sujeito vai construindo consigo mesmo, com o outro e com o mundo. São essas relações que possibilitam o sujeito se tornar presente para si, para buscar possibilidades de formação democrática para sua liberdade, de forma a impactar sua vida.

Isso nos leva a questionar e investigar o que fazem os estudantes nas aulas remotas a partir dessa posição subjetiva, dando lugar à sua posição de sujeito (in) submisso, bricolante e/ou (extra)ordinário.

\section{As INVENÇÕES (EXTRA)ORDINÁRIAS DOS ESTUDANTES NAS AULAS REMOTAS}

Inicialmente, um dos pesquisadores deste artigo entrou em um grupo de Whatsapp restrito apenas para estudantes do terceiro ano da turma investigada do Ensino Médio. Era um grupo paralelo a outro grupo oficial de discentes da escola pública estadual em voga. Neste grupo restrito, os estudantes falavam sobre suas angústias, teciam críticas aos professores, tiravam dúvidas sobre as atividades das aulas, além de manter conversas ordinárias. Após a aceitação de um dos pesquisadores no grupo, que explicitou os objetivos da pesquisa, foi enviado termo de Consentimento Livre e Esclarecido, para os que concordassem em participar da investigação e, posteriormente, o envio do link de perguntas que deveriam ser 
respondidas espontaneamente e enviadas pelo Google Formulário. Obtivemos um retorno de nove estudantes de um grupo de vinte, durante o prazo estipulado de sete dias para o feedback. A partir desse momento, o formulário de respostas seria fechado e não se aceitaria mais nenhum tipo de participação.

Esta é uma pesquisa de campo qualitativa, de cunho descritiva, tendo como base de análise de dados os conceitos de bricolagens, de Certeau (1998), e as noções da Relação com o Saber, de Charlot (2000; 2005; 2013). A produção dos dados se fez a partir de envio do Google Formulário, os quais possibilitaram desenvolvimento analítico do tema e sua discussão.

Para organização e compreensão das falas e da análise dos dados, designamos a letra E para os estudantes, e os numeramos de 1 a 9, perfazendo o total de participantes da investigação, e a letra $\mathrm{P}$ para os pesquisadores que produziram o formulário.

A primeira pergunta feita aos estudantes foi: $P$ - $O$ que vocêfaz durante as aulas on-line quando está com o áudio e a câmera ligada?

E5: Para ser sincera raramente eu acompanho as aulas online, assim como grande parte dos alunos eu entro na aula desligo a câmera e o áudio e vou fazer outras tarefas. Quando ligo apresento trabalho ou questiono algo. ${ }^{4}$

A resposta de $\mathrm{E}_{5}$ faz coro à maioria das respostas dadas pelos estudantes à primeira pergunta. A estudante parece não ter desejo pelas aulas on-line a ponto de que o mobilize a participar ativamente delas. E quando participa, com a câmera e áudio ligados, é somente para apresentar trabalho ou um questionamento sobre algo da aula; dúvidas, talvez. Ela encontra sentido em outra tarefa, que não a da aula, da qual "raramente" participa. A estudante $\mathrm{E}_{5}$ assina a lista de presença das aulas on-line; formalmente, ela "participa" das aulas mesmo fazendo outras atividades extras simultaneamente.

E8: Apenas acompanho, as vezes faço anotações. Durmo, faço outra atividade, procuro aulas mais relevantes ao vestibular.

E7: Estudo, participo conversando sobre o assunto com o professor e tiro minhas dúvidas. Eu acompanho.

4. As transcrições das respostas foram mantidas tais como foram escritas, sem correção de eventuais imprecisões gramaticais. 
O que fazer com o que as aulas remotas fazem comigo? Posição subjetiva de...

E9: O áudio eu ligo um pouco mais constantemente que a câmera, para explicar e acrescentar alguns fatos e observações [...] Normalmente quando a câmera está ligada é porque eu estou explicando/apresentando alguma tarefa como seminários ou outros projetos, faço isso principalmente quando quero passar mais confiança no que falo e garantir a atenção para a apresentação. Não acompanho quando não vejo futuro no objetivo da aula que muitas vezes é desinteressante, ou quando simplesmente de maneira explícita nem isso ela possui.

Os estudantes têm suas lógicas simbólicas próprias e encontram sentido nas aulas a partir delas. $\mathrm{O}$ estudante E8 deixa evidente seu interesse nas aulas que trazem contribuição para o vestibular e processos seletivos, e, a partir da realidade dos estudantes de escolas públicas, para o Exame Nacional do Ensino Médio (ENEM). Por outro lado, esse estudante também faz outras coisas, como "dormir", e, quando acompanha a aula, faz "anotações", mostrando, de certa forma, sua posição de sujeito de desejo, que se mobiliza e estuda apenas para aquilo que é de seu interesse e faz sentido diante da sua lógica de pensar sobre o assunto das aulas.

Já o estudante $\mathrm{E}_{7}$ descreve que "participa" das aulas sem maiores esforços e "acompanha" tirando "dúvidas" sobre os conteúdos abordados pelo professor. Ele também "estuda" nas aulas, o que demonstra, ao estar com a câmera e áudio ligados, interesse em participar das aulas.

O estudante E9 também participa das aulas remotas e traz na sua explicitação pontos que se destacam e fazem pensar sobre um sujeito que não é passivo diante do que acontece nas aulas remotas, o que nos leva a falar da posição subjetiva e de bricolagem do estudante que traz uma crítica ao professor e às aulas que não fazem sentido e são "desinteressantes", a partir do seu ponto de vista de pessoa que pensa e se mobiliza enquanto sujeito de desejo e que deseja aprender. $\mathrm{O}$ estudante entende que participa das aulas trazendo contribuições para que elas fiquem "mais dinâmica[s] e razoavelmente aceitável[eis]", ou seja, ele se coloca na posição empática para com o professor e age com recursos próprios para a dinâmica da aula. E quando percebe que a aula não faz nenhum sentido para ele, explicita: "não acompanho quando não vejo futuro no objetivo da aula que muitas vezes é desinteressante, ou quando simplesmente de maneira explícita nem isso ela possui", colocando-se na negação de estudar e de não participar de tal aula. Dessa forma, dar uma aula que não tem sentido para o estudante, o impede de participar dela e de entrar numa atividade intelectual, é negá-lo 
enquanto sujeito de desejo. Assim, é necessário que a aula tenha um bom motivo, um "móbiles"s para que o estudante se mobilize e encontre sentido, desejo e prazer nessas aulas remotas (CHARLOT, 2000; 2005; 2013).

No ambiente virtual das aulas remotas os estudantes se comportam como sujeitos insubmissos e fora de ordem de que fala Certeau (1998), e também enquanto sujeitos que refletem diante das condições que lhes são dadas nessas aulas; a partir delas encontram sentido, desejo, prazer, ou nada disso, em estudar (CHARLOT 2000; 2005; 2013), colocando-se fora da situação didática tanto física como intelectualmente - mesmo que esse ambiente seja virtual -, pois os mesmos podem desligar a câmera e o áudio e ainda assim estarão "presentes simbolicamente", mas seus interesses estão em outros lugares fora da aula.

Diante dessas explicitações dos estudantes elaboramos o segundo questionamento: $P$ - O que você faz durante as aulas quando você resolve não ligar a câmera e o áudio?

As condutas de comportamentos dos estudantes diante das aulas com câmera $\mathrm{e}$ áudio desligados são diversas e se sobressaem às regras, tirando proveito das possibilidades que o ensino remoto proporciona em favor de suas formas de acompanhar as aulas. Alguns deles assistem ["Apenas assisto" (E8)] ou ouvem o professor ["Fico ouvindo o professor $(\mathrm{a})$ " $\left.\left(\mathrm{E}_{7}\right)\right]$; outros, quando não estão ocupados, assistem às aulas ["Fico prestando atenção quando não estou ocupada" (E1)] ou fazem outras tarefas [ "resolvo outras tarefas" $\left(\mathrm{E}_{5}\right)$ ]. Há também aqueles estudantes que não encontram sentido nas aulas e ficam desatentos ["Fico desatento às aulas" ( $\left.\mathrm{E}_{3}\right)$, , $\mathrm{Me}$ distraio ou acompanho pelo chat com o professor e colegas” (E4)].

Destacam-se também os estudantes que produzem, trabalham e fazem outras coisas que não se referem às aulas, a exemplo da estudante E6: "além do estudo eu trabalho com artesanato, então ouço explicações e trabalho no mesmo horário, por exemplo, agora estou ouvindo explicação de uma aula e respondendo a este questionário", e do estudante $\mathrm{E}_{2}$, que procura uma forma de lazer e de estudar outras disciplinas quando à que está assistindo não lhe desperta o interesse, o que o faz desligar a câmera e o áudio ("nas matérias que não tenho 'simpatia', eu na maioria das vezes desligo a câmera, abaixo o volume e procuro fazer outra coisa, como tocar um violão ou me aperfeiçoar em matérias que eu gosto").

Já o estudante E9 comenta:

5. Móbiles é o bom motivo, o motivo do estudante se mobilizar, que faz sentido para ele. 
O que fazer com o que as aulas remotas fazem comigo? Posição subjetiva de...

E9: Quando não vejo futuro no objetivo da aula que muitas vezes é desinteressante, ou quando simplesmente nem isso ela tem, eu mantenho a câmera e o áudio desligados. Em seguida faço outras atividades mais proveitosas que a própria aula em si. Já os professores... Continuam como sempre fingindo estar ensinando enquanto os outros alunos fingem estar aprendendo, a famosa "educação do faz de conta" brasileira. (e possivelmente internacional a nível local).

Ele faz uma crítica sobre o ensino, sobre as aulas e os próprios estudantes em nível geral e local explicitando que é a "educação do faz de conta” brasileira. Quando ele se refere a essa educação, não é apenas a do momento atual de pandemia que tem em vista, mas a educação pré, durante e pós-pandemia. Além de criticar as aulas desinteressantes e sem objetivos, ele procura fazer outras atividades proveitosas, que não sejam da aula que está sendo oferecida.

Os estudantes agem, falam e refletem a partir de posições subjetivas, de um sentido de alguém que é um sujeito de desejo e que aprende de diversas formas, lugares e situações e questiona sobre o que aprende (dimensão epistêmica); os estudantes fazem parte de um grupo social popular, de uma comunidade e de situações sociais em que nem todos têm acesso ao computador e acessam as aulas com smartphone cuja internet é de péssima qualidade, com acesso até mesmo em ${ }_{3} \mathrm{G}$ (posição social). Esses estudantes têm suas histórias de vida, seus saberes, desejos e projeções presentes e futuras sobre o que lhe ensinam e o que desejam aprender (dimensão identitária). Dessa forma, os sentidos dos estudantes são multifacetados e ligados aos próprios sujeitos que são históricos, que estão inseridos numa posição social objetiva e subjetiva. E ao mesmo tempo fazem uso de bricolagens, procurando formas de se relacionar, produzir e estudar neste espaço de tempo das aulas remotas.

Com o objetivo de saber quais são as outras atividades que os estudantes fazem concomitante às aulas remotas, adentramos no segundo questionamento: $P$ - Vocêjáfez outra atividade que não correspondia à aula que você estava assistindo em algum momento?

Todos os estudantes fazem alguma outra atividade durante as aulas remotas pelo fato de ter atividades em excesso: "porque tem professores que estão passando muito dever" (E1) se acumulam "atividades de outras matérias, atrasadas por conta do amontoado de atividades" ( $\left.\mathrm{E}_{3}\right)$. Há casos em que se relata não haver tempo suficiente para estudar: "já estudei para um trabalho que ia apresentar na aula seguinte" (E5), e também aqueles em que se aproveita as aulas com que não se tem tanta afinidade para fazer coisas de outras disciplinas: "sim, recentemente 
tive uma aula de biologia e o professor passou um exercício, infelizmente acabou o horário dele e entramos na aula 'projeto de vida', a professora estava conversando e eu continuei fazendo o exercício de biologia” ( $\left.\mathrm{E}_{7}\right)$.

Outros estudantes fazem coisas que lhes dão prazer: "quando não acompanho, faço coisas que me dão prazer, alguma produção artística, jogo videogames, assisto filmes e séries, faço atividades de outras disciplinas que mais me interessem" (E9); ou que consideram proveitosas: "abaixo o volume e faço outra coisa, seja aperfeiçoar uma língua (espanhol, inglês), estudar outras matérias que considero mais proveitosas ou então procrastino ouvindo 'um sonzinho' no fone" (E2). Alguns aproveitam também para trabalhar: "quando a câmera e o microfone está desligado eu faço artesanato" (E6).

Eles também não participam de algumas aulas/disciplinas por acharem que não são importantes: "nossa, e muito! Por exemplo, Física (não em importação, pelo contrário, mas sim para estudar). Então, quando é aula de física, por exemplo, tem dias que não participo da aula, mas tem dias que entro na reunião" $\left(\mathrm{E}_{2}\right)$. Outros estudantes fazem pesquisa e outras coisas que têm mais sentido para eles: "ainda estudo indiretamente através de pesquisas sobre temáticas que me despertam interesse, estudo verdadeiramente, diferente do que acontece no colégio... E outras vezes apenas prefiro ficar sozinho comigo mesmo, refletindo sobre a vida e o mundo, apenas permaneço num tédio que eventualmente vira ócio criativo” (E9).

Os estudantes usam das suas posições subjetivas e se mobilizam a partir de recursos próprios para se ocuparem com outras coisas, como trabalho e atividades diversas, passando a exercer atividade intelectual para aprender saberes que não são das aulas, mas voltados ao aperfeiçoamento de uma língua, à produção artística e ao lazer.

Os estudantes desta pesquisa não se mostram passivos diante das aulas remotas. Eles também se mobilizam por coisas que acham interessantes e que geralmente não são assunto da aula a que assistem, coisas que de alguma forma trazem algum benefício ou prazer. $\mathrm{O}$ que se evidencia aqui é o fato de que os estudantes podem escolher o que fazer nas aulas remotas mesmo sem o consentimento do professor e isso não lhes causa prejuízos. Não há ônus durante as aulas e o período letivo, pois os estudantes conseguem acompanhar as disciplinas mesmo fazendo coisas "mais interessantes" concomitantemente. Ao mesmo tempo, eles sentem uma sobrecarga de atividades nas disciplinas. As formas pelas quais os estudantes se sobressaem nas aulas remotas são diversas e o desejo é fazer algo que lhes dê prazer e que faça sentido; eles usam bricolagens como formas de produção ou lazer nas aulas. 
O que fazer com o que as aulas remotas fazem comigo? Posição subjetiva de...

Diante de possíveis dificuldades fizemos o quarto e último questionamento: $P$ - Diga o que você acha dessa modalidade de ensino nesse momento de pandemia, suas dificuldades e as vantagens de acordo com sua experiência.

Os estudantes da escola pública encontraram diversas dificuldades diante desse último questionamento que fizemos, desde relatos de falta de tempo: "assim... para mim está sendo difícil porque não é sempre que estamos desocupados e a aprendizagem está muito lenta” ( $\left.\mathrm{E}_{1}\right)$, até falta de acesso à internet de boa qualidade e o estresse causado por essa situação: "acho chato, estressante, prefiro presencialmente. O ensino não é igual principalmente aos que não possuem acesso a internet" ( $\left.\mathrm{E}_{4}\right)$. Eles também relatam a desorganização das aulas e acabam não aprendendo: "Um desastre. Escola totalmente desorganizada. Não vejo nenhuma vantagem, os malefícios são muitos, dentre eles a pouca garantia de conhecimento" (E8).

Alguns dos estudantes falaram sobre as dificuldades que encontram nas aulas remotas. Não veem vantagens nelas e também encontram dificuldades de conexão à internet, além de se queixarem do excesso de atividades e da qualidade da aula remota. Vejamos o estudante E2:

Não acho a melhor maneira de se aprender, porém, vejo que as instituições (como Estado e escola) estão tentando buscar novas maneiras para tentar melhorar o ensino. Bom, no quesito dificuldades, tem a questão da Internet, que às vezes a conexão ou minha ou a do professor na reunião fica ruim, e tem também sobre o excesso de atividades que alguns professores propõem. As vantagens eu não vejo muitas. Nunca as aulas virtuais substituirão da mesma eficiência as aulas presenciais (físicas).

A estudante $\mathrm{E}_{7}$ fala sobre sua maior produtividade e aproveitamento nas aulas presenciais, as dificuldades de estudar em casa, as desinformações dos professores e o excesso de atividades que se acumulam:

Eu sou muito mais produtiva nas aulas presenciais do que nas aulas online. Nas aulas online, acabo não me dedicando tanto... é como se nessa nova modalidade de ensino fosse tudo em dobro sabe? Tem professores que nem se apresentam ou explicam algo referente à atividade que passou, só deixa lá no Google sala de aula e pronto, acho isso deprimente. Uma das minhas maiores desvantagens é ter que estudar em casa, digo isso porque agora ficamos "o tempo todo" em casa, é bem mais difícil de se concentrar (seja por algum problema familiar, barulhos...) Consequentemente fica mais fácil de 
procrastinar. Uma das minhas vantagens é tentar sempre adiantar o máximo que conseguir, digo isso referente a assuntos, exercícios... Se não faço isso, posso ficar cheia de deveres acumulados... Sou grata por ter acesso a essa nova modalidade de ensino, enquanto muitos infelizmente não têm. Mas desejo que isso acabe o quanto antes.

O excesso de atividades e conteúdos, problemas no acesso à internet, dificuldade de concentração por não ter lugar adequado para estudar em casa são os assuntos mais destacados entre os estudantes: "dificuldade: a maior é a concentração. No ambiente escolar 'todos' estão com o mesmo sentido (concentrar e estudar), já em casa as pessoas ao nosso redor de certa forma dissipa nossa atenção. Vantagens: estudar fora do ambiente escolar que algumas vezes é estressante" (E6). Pôde-se ver também coisas como: "dificuldades no acompanhamento na aprendizagem de todos os alunos, e muitas atividades que acabam prejudicando alguns alunos que buscam aprovação no vestibular, mas como a última alternativa é aulas online” ( $\left.\mathrm{E}_{3}\right)$.

Os estudantes têm ciência de que as aulas remotas estão sendo necessárias para o momento de pandemia, a fim de que não haja perda do ano letivo; não obstante, relatam os problemas que elas trazem para suas vidas: "então, o momento é complicado e delicado, as aulas não presenciais foram necessárias para que não perdêssemos o ano letivo de 2020. Mas está sendo difícil o entendimento das matérias exatas e também pela falta de compreensão de alguns professores que passam muitas atividades e trabalhos" ( $\left.\mathrm{E}_{5}\right)$.

Por último, tivemos o relato do estudante E9, que trouxe algumas reflexões:

Tecnologias quando popularizadas são facilmente estragadas, tal como acontece com as plataformas de ensino online. A escola possui fundamentalmente como sentido principal, a socialização. Quando essa socialização sai da equação, os alunos se tornam impotentes, assistir a aula se torna ainda mais desinteressante e, o sentido do conceito da escola acaba. Visto que a motivação encontrada inicialmente que mobilizava determinado indivíduo para aulas online era exterior ao colégio, como vestibulares e carreira profissional. Em grande parte, sem essa possibilidade de socialização (fisicamente), na prática, a escola fracassa brutalmente.

A escola, para o estudante E9, tem como função fundamental a socialização dos estudantes. Para ele, as aulas remotas negam essa socialização, culminando na falta de interesse pelo estudo, de modo que "o sentido do conceito da escola acaba". Para 
O que fazer com o que as aulas remotas fazem comigo? Posição subjetiva de...

Charlot (2000; 2005), um dos principais motivos que levam os estudantes para a escola é a socialização, pois a escola, além de um lugar de saber, é também lugar de encontro com os colegas. Esse estudante ainda fala da motivação que mobilizava os estudantes a estudar e que se perdeu com as aulas remotas. Para Charlot (2000; 2005; 2013), motivação e mobilização são distintas. Motivação é algo externo ao sujeito, vem de fora e tem propriedade efêmera. Já a mobilização é uma força interna, energia que vem do próprio sujeito que encontra um "mobiles" causado pelo desejo de se movimentar. Desejo e sentido são mola propulsora necessárias de mobilização para as aulas remotas.

As dificuldades levantadas pelos estudantes da escola pública estadual em voga na pesquisa causam desconfortos no seu processo de aprendizagem. Não obstante, as aulas remotas lhes possibilitam a criatividade nas formas de transgredir o ensino e a própria aprendizagem, de forma que elas corroborem a seu favor diante das circunstâncias que lhes são impostas. Os estudantes pensam, agem, se mobilizam, entram em atividade intelectual, estudam e aprendem. Eles também usam de bricolagens, desviam-se, negam o ensino, saem da ordem, quebram protocolos e se sobressaem nas situações ordinárias da escola, que agora é virtual e conta com aulas remotas. Como sujeitos de relações consigo mesmos, o outro e o mundo, os estudantes não são passivos à ortopedia da Educação; eles também têm desejos, objetivos, metas e estão sempre em mobilização para alcançá-los a curto ou longo prazo.

\section{ConClusão}

A partir das contribuições dos resultados e discussões desta pesquisa é possível dizer que os estudantes das escolas públicas têm, de fato, a liberdade e o direito de autonomia, de tomar decisões e de exercer atividade intelectual na sala de aula, a partir de um estatuto de legitimidade do ensinar e do aprender - pois é para eles que o ensino e a aprendizagem são direcionados. Que o próprio estudante possa se perceber como sujeito de desejo e de direito no sistema educacional e mais ainda no processo de aprendizagem remota; que, além disso, traga sua contribuição, junto com seus pares, à escola.

A partir da visão de Certeau (1998), o tipo de estudante visto nesta pesquisa é aquele que abala as normas vigentes, concretas, pois essas não fazem o discente se tornar outra coisa além de um estudante que obedece, cumpre, "aprende", e que não passa apenas de um reprodutor e/ou um produto social. Não obstante, as ações dos estudantes nas aulas remotas são permeadas de bricolagens como formas de viver dentro do ambiente virtual e de se superar nele. 
Para Charlot (2000, p. 82), somos sujeitos "engajados em uma dinâmica do desejo" e, enquanto portadores de um estatuto do desejo, os estudantes entram em mobilização diante das disposições às quais as aulas remotas os expõem e de suas posições subjetivas, encontrando sentido em coisas, assuntos e saberes dentro e fora dessas aulas. Uma vez que a escola ainda se encontra com seu papel normativo e disciplinador, os estudantes, por meio de recursos próprios, também são bricolantes e se sobressaem a essas normas e, sobretudo, ainda aprendem.

\section{REFERÊNCIA}

BOURDIEU, P; PASSERON, J. C. A Reprodução: elementos para uma teoria do sistema de ensino. Rio de Janeiro: Livraria Francisco Alves Editora, 1992.

UNESCO. TIC Educação 2019: coletiva de imprensa. São Paulo, 2020. Disponível em: https://cetic.br/ media/analises/tic_educacao_2019_coletiva_imprensa.pdf. Acesso em: 10 de novembro de 2020 . CERTEAU, M. de. A invenção do cotidiano: artes de fazer. Trad. Ephraim Ferreira Alves. 3. ed. Petrópolis/RJ: Editora Vozes, 1998.

CHARLOT, B. Da relação com o saber: elementos para uma teoria. Trad. de MAGNE, B. Porto Alegre: Artmed, 2000.

CHARLOT, B. Relação com o Saber, Formação dos Professores e Globalização: questões para a educação de hoje. Porto Alegre: Artmed, 2005.

CHARLOT, B. Da relação com o saber às práticas educativas. São Paulo: Cortez, 2013

\section{SOBRE OS AUTORES}

Eanes dos Santos Correia. Licenciado em Educação Física, Mestre em Ensino de Ciências Naturais e Matemática e Doutorando em Educação pela Universidade Federal de Sergipe. Membro do Grupo de Estudo e Pesquisa Educação e Contemporaneidade - EDUCON/UFS/CNPq.

ORCID ID: http://orcid.org/oooo-0oo2-9188-4336.

E-mail: eanescorreia1@gmail.com.

Veleida Anahi da Silva. Licenciada em Ensino de Ciências e Matemática, Doutora em Ciências da Educação pela Universidade de Paris VIII, docente do Programa de Pós-Graduação em Ensino de Ciências e Matemática e em Educação da Universidade Federal de Sergipe. Líder do Grupo de Pesquisa Educação e Contemporaneidade - EDUCON/UFS/CNPq. 
O que fazer com o que as aulas remotas fazem comigo? Posição subjetiva de...

ORCID ID: http://orcid.org/oooo-ooo2-0920-5884.

E-mail: vas.charlot@gmail.com.

Willdson Robson Silva do Nascimento. Licenciado em Física, Mestre e Doutorando no Programa de Pós-Graduação em Educação para a Ciência pela Universidade Estadual Paulista "Júlio de Mesquita Filho" Campus Bauru. Membro do Grupo de Estudo e Pesquisa Educação e Contemporaneidade EDUCON/UFS/CNPq.

ORCID ID: http://orcid.org/oooo-0002-2350-7731.

E-mail: willdsonnascimento@gmail.com.

Recebido em 16 de fevereiro de 2021 e aceito em 14 de julho de 2021. 